\title{
EL CONCEPTO NORMATIVO DE LA CULPA COMO CRITERIO DE DISTRIBUCIÓN DE RIESGOS. UN ANÁLISIS JURISPRUDENCIAL*
}

\author{
THE CONCEPT OF GUILT AS LEGAL STANDARD OF DISTRIBUTION \\ OF RISK. A JURISPRUDENCE ANALYSIS
}

\begin{abstract}
Cristián Aedo Barrena**
RESUMEN: El presente artículo hace un análisis de la jurisprudencia chilena, con el propósito de demostrar que la culpa se emplea como herramienta de distribución de riesgos entre la conducta que debe ser asumida por el potencial dañante y el ámbito de cuidado de la propia víctima. Se sostiene que, en los casos en que el concepto de la culpa se utiliza para hacer responsable al dañante de todos los riesgos derivados de una actividad, el concepto de culpa resulta deformado, porque el autor del daño no responde conforma a un patrón o estándar medio de conducta. Excepcionalmente, en los casos en que la actividad es de peligro intrínseco ( $\mathrm{y}$ en ausencia de régimen legal que consagre la responsabilidad estricta), consideramos correcta la interpretación jurisprudencial, en orden a admitir, solo en este grupo de casos, la presunción por hecho propio consagrada en el artículo 2329 del Código civil.
\end{abstract}

Palabras clave: Culpa, riesgo, presunción por hecho propio

ABSTRACT: This paper makes an analysis of the jurisprudence, in order to prove that the fault is used as a tool for risk sharing between the behavior that must be assumed by the potential tortfeasor and scope care the victim. It is argued that, in cases in which the concept of guilt is used to make the responsible for all the risks of an activity, the concept of fault is deformed because the tortfeasor does not respond or conform to a standard pattern through conduct. Exceptionally, in cases where the activity is intrinsic hazard (and in the absence of legal regime that establishes strict liability), we consider the correct legal interpretation, in order to admit, only in this group of cases, the presumption for one's own enshrined in Article 2329 of the Civil Code.

Key words: Guilt, risk, presumption for one's own

\section{INTRODUCCIÓN}

Hay consenso en que la culpa constituye hoy día la mejor herramienta de distribución de los daños en un sistema de responsabilidad civil, de modo que, a pesar de las

\footnotetext{
* Este artículo forma parte del proyecto Fondecyt de iniciación $N^{\circ} 11121533$, titulado "Las relaciones entre la culpa y la causalidad: una reflexión de la experiencia romana”, del cual el autor es investigador principal y del proyecto Anillo de Investigación Asociativa, patrocinado por la Comisión de Investigación Científica y Tecnológica, bajo el Código SOC 1111: "Estudios dogmáticos del Derecho patrimonial privado", del cual el autor es investigador asociado.

** Doctor en Derecho por la Universidad de Deusto. Profesor de Derecho romano y civil en la Universidad Católica del Norte. Correo electrónico de contacto: caedo@ucn.cl.
} 
numerosas críticas de las que ha sido objeto, ${ }^{1}$ constituye el factor atributivo sobre el cual se articula el régimen común, ${ }^{2}$ reservando las hipótesis de responsabilidad estricta para ámbitos en los que, por regla general, las actividades suponen un riesgo inherente para las potenciales víctimas. ${ }^{3}$

¿Qué es la culpa para la responsabilidad civil extracontractual? En la dogmática moderna, es mayoritaria la idea de que la culpa debe ser definida como la infracción del deber de cuidado. A ello se le denomina, precisamente, el concepto normativo de la culpa, que se traduce en la apreciación en abstracto de la conducta, es decir, por comparación con un estándar objetivo. ${ }^{4}$

A nuestro juicio, sin embargo, la cuestión sobre el concepto de la culpa no queda resuelta al afirmar que esta se traduce en la vulneración de un estándar de comportamiento social. En primer lugar, porque es necesario reflexionar sobre aquello que configura la médula del concepto normativo, a saber, el estándar de comportamiento: ¿cómo se construye este estándar?; y, ¿qué límites hay en su construcción?, ¿cuál es la función del estándar en el sistema de responsabilidad extracontractual? Todo ello es sin perjuicio de que, en nuestro concepto, no puede comprenderse acabadamente un concepto sino se estudia este en sus relaciones con los restantes elementos de la responsabilidad. De esta cuestión ya nos hemos ocupado en otro lugar. ${ }^{5}$

1 Véase, entre otros, Ripert (1949) pp. 200-203; Rodotà (1965) pp. 18-25; Reglero (2008) t. I, p. 251; YzQuierdo (2008) pp. 218-219; Díez-Picazo (2011) pp. 103-105. En el Derecho chileno, por todos, Corral (2004) pp. 85-87.

2 En la dogmática chilena, véanse, entre otros, Rodríguez Grez (2001) p. 63; Corral (2004) p. 73; Barros (2009) pp. 16; 27-28; 75. En la doctrina comparada, entre otros, Bianca (1997) pp. 138-139. También, Dí́zZPicazo y Gullón (2005) p. 540. De Ángel (1993) pp. 126-127; Díez-Picazo (2001) p. 164. La vigencia actual de la culpa no puede ponerse en duda, pero tampoco puede dudarse que la culpa misma se ha visto afectada en algunas de sus funciones, como ha puesto de manifiesto Viney. De un lado, en cuanto la culpa designaba el patrimonio sobre el cual se hacía efectiva la responsabilidad del deudor, los sistemas de seguros y colectivos se tradujeron, en los hechos, en un reemplazo o declive de la culpa, pero, como contrapartida, comenzó a emplearse en la valoración de los perjuicios, estimando la gravedad de la falta como un mecanismo de recuperación de sus primigenias funciones preventivas y punitivas. Véase VINEY (1965) pp. 211; 215 y ss.

3 Para este punto véase YusefF (2000) pp. 219 y ss. Una idea similar ha expresado nuestra jurisprudencia, resolviendo un problema de responsabilidad extracontractual del Estado, por falta de servicio. Véase, Empresa de Transportes Pucará con Fisco de Chile (2008): Corte de Apelaciones de Santiago, 10 de enero de 2008, rol 362003, indicador Microjuris MJJ16341, la Corte declaró: "La responsabilidad del Estado no es objetiva, vale decir, el daño debe ser causado por la actuación culpable o dolosa de un órgano o ente estatal. En Chile la responsabilidad objetiva tiene el carácter de excepcional, solo se aplica en los casos que la ley lo determina”.

4 En la dogmática chilena, es opinión que consideramos mayoritaria. Véase, Corral (2004) pp. 210-211; Alessandri (2005) pp. 126-127; TAPIA (2006) p. 157; BARros (2009) pp. 77-78. En algunas obras dedicadas a sectores especiales de la responsabilidad civil, también se sigue el mismo criterio. Véase, en este sentido, Guajardo (2005) p. 182; Alcalde (2013) p. 106. En el derecho comparado, Díez-Picazo (2001b) pp. 112 y ss. Montés Penadés considera que el sentido propio de la culpa es el siguiente: "culpa es siempre un comportamiento no ajustado a los cánones éticos, y ese comportamiento contiene un elemento de imprevisión, o de falta de diligencia, o de impericia”, pero luego indica que no se encuentra envuelta en la culpa la pura cuestión de la imprevisión, que conduce a un concepto psicológico, sino que esta debe ser definida normativamente, en relación con el comportamiento dañoso y requerido por el ordenamiento. Montés Penadés (2003).

5 Véase nuestros trabajos AEdo (2010) pp. 213-239; AEdo (2012) pp. 777 y ss. 
A partir del análisis de la jurisprudencia, la hipótesis de nuestro trabajo es que la culpa constituye una herramienta de distribución de riesgos sociales: el estándar de conducta medio que supone el denominado deber de cuidado, plantea una delimitación entre los ámbitos de control del potencial autor del daño y el ámbito en que la víctima debe asumir medidas de cuidado. La perspectiva que aquí se afirma, como veremos, ha sido defendida por un sector del análisis económico del Derecho, pero en nuestro trabajo se intenta conciliar esa mirada con la perspectiva dogmática y con el análisis de la jurisprudencia chilena.

Nuestro planteamiento pretende reflexionar, del mismo modo, sobre los límites en la construcción del estándar, porque, en efecto, la jurisprudencia chilena emplea erróneamente la culpa a nuestro juicio, cuando pone a cargo del responsable del daño todos los riesgos derivados de una actividad, ${ }^{6}$ salvo en los supuestos de actividades de riesgo intrínseco que no se encuentran regulados legalmente. Frente a este grupo de casos, la jurisprudencia chilena ha resuelto el problema recurriendo a la presunción de culpa por hecho propio, consagrada, para un sector de la doctrina, en el artículo 2329 del Código civil. Pensamos que esta solución, en la medida que sea excepcional, satisface el adecuado funcionamiento de la culpa, como se argumentará.

\section{LA CULPA COMO INFRACCIÓN DE REGLAMENTOS: CULPA CONTRA LA LEGALIDAD}

La culpa como infracción normativa se traduce en lo que la dogmática chilena identifica, desde Alessandri, como la culpa contra la legalidad y se configura en las hipótesis en que la ley establece directamente el estándar de conducta. Es claro que dicho concepto puede aplicarse a esferas sociales limitadas, como por ejemplo, la responsabilidad civil derivada de accidentes de tránsito.

En efecto, en la dogmática chilena, se considera que el análisis de la norma resulta inoficioso si se ha violado una obligación proveniente de una norma determinada. En particular Alessandri piensa que esta culpa se configura cuando la autoridad establece claramente una prohibición, a objeto de precaver un perjuicio o daño. ${ }^{7}$ Para Barros, una de las formas de construcción del deber de cuidado, se encuentra en la violación de normas (legales o reglamentarias), destinadas a regular específicamente una actividad, a priori, peli-

\footnotetext{
${ }^{6}$ Es un problema que se ha presentado también en el Derecho comparado. Como advierte De Ángel, hay amplios campos en los que el concepto de la culpa se ha ido deformando, no solo por la objetivación legislativa, sino porque en determinados terrenos problemáticos la jurisprudencia ha estrechado el concepto de la culpa al punto de convertirla en una responsabilidad estricta, como ocurre con la responsabilidad del empresario. DE Ángel (1993) pp. 351 y ss.; De Ángel (1995) pp. 32-33. Jourdain (1994) p. 16 también ha denunciado una progresiva deformación del concepto de culpa a través de las decisiones de los tribunales, quienes han llegado a considerar como culpa simples errores moralmente insignificantes, fruto de la torpeza o el mal manejo, lo que trae el peligro de confundir el error con la culpa, insistiendo, de la mano de Tunc, sobre el carácter estadísticamente inevitable y por tanto, perdonable de ciertos descuidos.

7 Alessandri (2005) pp. 128-129. Sigue posición, Abeliuk (2003) p. 210; Corral (2004) p. 215; Ramos PaZOS (2006) p. 53.
} 
grosa. En estos casos, según el autor, cuando el daño se produce por la violación normativa, el acto es tenido por ilícito, que Barros equipara a la culpa. ${ }^{8}$

En un sentido similar, la Corte Suprema, en la sentencia de 18 de enero de 2012, ha declarado que para que prospere la responsabilidad fundada en la culpa contra legalidad, es necesario que el daño haya sido causado por la infracción normativa. En la causa se había demandado a la empresa ESVAL S.A. por un incendio producido en Viña del Mar, al que las distintas Compañías de Bomberos no pudieron hacer frente adecuadamente, al existir una baja presión de agua en los grifos. La parte demandante intentó construir la responsabilidad civil desde la infracción normativa que regulaba el mantenimiento de grifos. Al respecto, dijo la Corte: "A su vez, tampoco se configura en la especie una presunción de culpa por la infracción de normas reglamentarias, tesis que sostiene que cuando se infringen deberes de cuidado impuestos por la normativa, la sola infracción de ellos permite desprender culpa o negligencia del infractor. Sin embargo, la tesis de la culpa contra la legalidad supone que esté establecida la infracción de las normas que imponían deberes de diligencia y, en la especie, no quedó asentado que ESVAL S.A. vulnerara la reglamentación sobre la prestación del servicio de grifos ni las normas sobre presión o caudal de agua".

Como se ha dicho supra, las causas en las que la culpa se configura como culpa contra legalidad, son hipótesis de accidentes de tránsito, como por ejemplo, en la sentencia de la Corte de Apelaciones de Antofagasta, de 7 de noviembre de 2012: "Decimoséptimo: Que para que exista responsabilidad extracontractual se requiere efectivamente culpa por parte del agente, pero este concepto debe tomarse en el sentido propio de la responsabilidad civil como una infracción del reglamento, y en este caso, el conductor del taxibús al enfrentar un cruce con luz amarilla, lo hizo a exceso de velocidad, a $72 \mathrm{~km} / \mathrm{h}$ en una zona de escuela en horario de entrada y salida de los alumnos, por lo que no podía circular a más de $30 \mathrm{~km} / \mathrm{h}$, impactando a la menor ya individualizada, quien atravesó la calzada corriendo y como consecuencia del impacto, falleció”. ${ }^{10}$

Al margen de los supuestos de accidentes ferroviarios o de tránsito, en algunas ocasiones nuestros tribunales han despejado el problema de la culpa, recurriendo a la infracción de una norma. Como por ejemplo, en el fallo de la Corte Suprema, de 5 de marzo de $2007 .{ }^{11}$ Los hechos que fundaron la demanda de indemnización fueron los siguientes: El

8 Barros (2009) p. 98. Como indica el propio Barros (2009) pp. 97; 132, en responsabilidad civil, la antijuridicidad no es nada más que el hecho culpable que causa daño y agrega que: "quien dice que un acto es culpable dice también que es antijurídico y viceversa”.

9 Compañia de Seguros Euroamérica con Esval S.A. (2012): Sentencia de la Corte Suprema, 18 de enero de 2012, rol 3391-09, indicador Microjuris MJJ30873.

10 Zamora González, Marisol con Villela Mina, Richard (2012): Corte de Apelaciones de Antofagasta, 7 de noviembre de 2012, rol 500-12, indicador Microjuris MJJ34016. Véase también, Díaz Figueroa, Jacqueline con Zuloaga Tapia, Jeanette (2010): Corte de Apelaciones de La Serena, 26 de julio de 2010, rol 1-2010, indicador LegalPublishing CL/JUR/4400/2010; Moya Jérez, Amada con Importadora y Exportadora Comercial Foto Eléctrica Flash Limitada (2002): Corte de Apelaciones de Santiago, 31 de diciembre de 2002, rol 67.454-1999. Un típico caso de accidente ferroviario resuelto con el expediente de la culpa contra legalidad, véase Orrego Pardo, Emilio con Empresa de Ferrocarriles del Estado (1938): Corte de Suprema, 26 de agosto de 1938, indicador LegalPublishing CL/JUR/2/1938.

${ }_{11}$ Castilla y otros con Empresa Eléctrica Austral (2007): Corte Suprema, de 5 de marzo de 2007, rol 603-2006, indicador CL/JUR/5740/2007; 36120. Véase también Farías Soruco con Sociedad Comercial Andalucía Limitada 
16 de septiembre de 1999, aproximadamente a las 13:00 horas, dos menores ingresaron al recinto donde se encontraba ubicada la central, cuyos accesos estaban controlados por vigilantes privados; los menores burlaron el control y escalaron el primer cierre perimetral de la referida Central Generadora, constituido por un cerco de alambre, de dos metros de altura y dos hebras de alambres de púas a una distancia aproximada de 25 centímetros una de la otra y a 20 centímetros del extremo superior del cierre de alambre, y posteriormente reptaron por la parte inferior del segundo cierre de protección atravesando un espacio no superior a 20 centímetros. Ambos fallecieron electrocutados. No obstante, la Corte entendió que había responsabilidad de la empresa, al no haber respetado la norma reglamentaria que regulaba la construcción de los cierres perimetrales de este tipo de instalaciones. Según la Corte: "La norma 6.2.6. señala que la altura mínima "deberá aumentarse por lo menos a $2.50 \mathrm{~m}$ si el cierro linda con un sitio público, y a la parte superior del cierro se le agregará una protección contra escalamiento . Las fotografías de fs. 25, 29, 30, 64, 70, 73, 74, 76, 238, 239, 244 y 19 de la causa tenida a la vista y el croquis de fs. 218 permiten observar que el recinto donde estaba la Central colindaba con caminos y con espacios abiertos, esto es, con "sitios públicos pero de acceso restringido, controlado por el guardia ubicado en el ingreso del Parque Industrial. En consecuencia, debe concluirse que la demandada no cumplió con la altura mínima del cierro perimetral exigida por la norma pues medía como máximo, con las hebras de alambre de púas, 2:45 o 2.50 metros, en circunstancias que la altura debía ser superior".

\section{LA CULPA COMO INFRACCIÓN DE UN ESTÁNDAR SOCIAL: LA POSICIÓN NORMATIVA SUSTANCIAL}

En nuestra doctrina, la consideración de la culpa contra la legalidad no es obstáculo para estimar que el deber de cuidado se construye, del mismo modo, bien a partir de infracción de usos normativos, ${ }^{12}$ bien mediante la determinación del deber de cuidado por el juez; en otros términos, la aceptación de una concepción de la culpa normativa formal convive con otra, sustancial, que refiere el comportamiento debido, en definitiva, a la decisión jurisdiccional.

En ausencia de usos normativos e incluso, a pesar de ellas, el estándar de conducta es construido por el juez. ${ }^{13}$ Algunos autores han propuesto que el estándar de conducta con

(2007): Corte de Apelaciones de Rancagua, 23 de julio de 2007, rol 1632-2006, indicador LegalPublishing CL/JUR/1439/2007.

12 Barros (2009) p. 104. Antes AlesSANDri (2005) pp. 132-133, había reconocido expresamente la configuración del deber de cuidado a partir de la infracción de reglas profesionales o bien de usos y hábitos. Véase también, en el mismo sentido, RodríGuez Grez (1999) pp. 178-179.

${ }_{13}$ Excepcionalmente la jurisprudencia ha entendido que el cumplimiento normativo supone automáticamente diligencia, véase Pérez Rivera, Rafael con Banco Santander (2000): Corte de Apelaciones de Copiapó, de 6 de julio de 2000, causa rol 6.799, indicador LexisNexis 19.529. Los hechos que motivaron la causa, fueron los siguientes: al actor le fue cobrado indebidamente un cheque por un tercero, por la suma de $\$ 600.000$. El actor dio orden de no pago por extravío del documento y, en cumplimiento de dicha orden, el banco no pagó el documento, lo que supuso acciones criminales en contra del actor. Según el demandante, el banco demandado debió haber negado el pago en atención a la caducidad del cheque, antes que a la orden de no pago. Según la 
el que debe construirse el juicio de culpa, es el del buen padre de familia. Es la posición de Alessandri, quien sostenía que para apreciar la culpa debía recurrirse al estándar del buen padre de familia, tanto porque el artículo 44, al definir la culpa, es aplicable el ámbito contractual, como porque el artículo 2323 recurre a dicho estándar para su determinación. Aun así, no propone un único modelo para todo tipo de situación, sino uno que puede variar según el tiempo, el lugar, la condición social, la profesión, en fin, las circunstancias denominadas externas, frente a aquellas internas, que no deben considerarse. ${ }^{14}$ Esta misma posición adopta Corral. ${ }^{15}$

Aunque comparte el principio de la aplicabilidad del artículo 44, Barros ha hecho un esfuerzo para determinar, con mayor precisión y profundidad, el modo en que el estándar debe ser construido. Según Barros, la tendencia del derecho comparado es considerar bien las expectativas recíprocas de comportamiento, bien el cuidado exigido a una persona razonable enfrentada en las mismas circunstancias, lo que le conduce a estimar que no puede haber otra conclusión que considerar el patrón de la culpa leva, consagrado en el artículo 44 del Código civil. Ahora bien, en concordancia con toda la doctrina chilena, Barros entiende que en la construcción del modelo es esencial la consideración de las circunstancias extrínsecas (lugar, medios, riesgos, costos, naturaleza de la actividad emprendida, derechos e intereses en juego). En cambio, en principio, considera que las circunstancias especiales del sujeto, aun aquellas que se discuten (como la edad, el sexo o las cualificaciones profesionales), porque, de ese modo, explica Barros, se corre el peligro de crear un estatuto de responsabilidad diferenciado según el sujeto. Como el Derecho civil y el sistema de responsabilidad se basan en la igualdad, cada sujeto debe soportar sus propias debilidades (aunque en el supuesto de debilidades emocionales y psicológicas, puede ocurrir, según Barros, que la responsabilidad sea del autor del daño). Por eso Barros entiende que si bien es cierto el modelo es abstracto, su determinación es en concreto, especialmente cuando la determinación del modelo la realiza el juez. ${ }^{16}$

En suma, el modelo se configura como patrón, en parte abstracto, en relación con el sujeto cuya conducta se analiza; y en concreto, en relación con las circunstancias de cada caso. Es cierto que el juez no puede colocarse en la misma situación del dañante, porque la evaluación de la culpa constituye un juicio ex post. Incluso, no podríamos colocar al mismo sujeto en idéntica situación, pues las circunstancias concretas jamás se repetirían.

Veamos algunas sentencias, que dan cuenta que, en términos generales, las soluciones jurisprudenciales se encuentran acordes a la tesis normativa de la culpa. Un número importante de sentencias, en los distintos tribunales superiores del país y en variados ámbitos de la responsabilidad (desde el régimen general hasta los llamados regímenes especiales), emplean un criterio normativo de la culpa, aunque deba destacarse que, en la mayoría de

Corte, no puede atribuirse culpa alguna al Banco, ni infracción al contrato de cuenta corriente, porque el Banco había cumplido estrictamente las disposiciones legales que regulaban la materia.

14 Alessandri (2005) pp. 126-127. Véase también Rodríguez Grez (1999) pp. 182-184.

15 Corral (2004) pp. 212-213.

16 Barros (2009) pp. 84-89; 105-107. 
los casos, no se hace referencia a ella como infracción de un deber de cuidado, sino como un reproche a partir de un estándar de conducta.

En el fallo de la Corte de Apelaciones de Concepción, de 20 de julio de 2000, se resolvió el siguiente problema. Pesquera Sur de Exportaciones Limitada demandó a don Esteban Salinas, patrón de la nave Pablo III. El demandado hizo ingreso a una zona claramente demarcada, perteneciente a la demandante, extendiendo redes para faenas de pesca, que generó la pérdida de 25.000 kilos de alga húmeda, además de numerosos daños en la infraestructura. Dice la Corte, en el considerando segundo: "Que en la especie se estableció por el juez a quo que en el mar, el lugar de la concesión se encontraba clara y visiblemente demarcado en toda su extensión, lo que incluso reconocen los propios testigos de la demandada, y además, que el hecho aconteció en pleno día, a pesar de lo cual el patrón del barco pesquero Pablo III, Esteban Salinas, ingresó en él y caló la red para pescar. Lo que se dice, acorde con lo expresado en el raciocinio que antecede, y contra lo concluido sobre el particular por el sentenciador de primer grado, es insuficiente para acreditar la existencia de dolo por parte del patrón pesquero aludido. Pero, lo acotado revela que hubo de su parte falta de cuidado. Su actitud indica carencia de diligencia, descuido e imprudencia, que fue lo que motivó el daño, aunque no se haya comprobado la intención de ocasionarlo, y como para él era previsible, en las condiciones señaladas, que al lanzar las redes para pescar dañara la plantación de algas, su obrar fue culpable y generador de responsabilidad civil". ${ }^{17}$ En otras palabras, lo concreto son las circunstancias, no la conducta, la que es valorada acorde a lo que debe esperarse de un sujeto en idéntica posición.

En la sentencia de la Corte de Apelaciones de Santiago, de 26 de abril de 2012, se dijo que la culpa correspondía a la violación de un deber de cuidado objetivo. Dijo la Corte, en el considerando segundo que: "el concepto jurídico de culpa o negligencia se refiere a la no observancia de las exigencias típicas y objetivas de cuidado que las personas deben observar en su vida de relación. En consecuencia, para determinar si concurre uno de los requisitos de la responsabilidad civil por culpa o negligencia, resulta indispensable determinar la regla de conducta que una persona prudente y diligente habría observado en el caso particular que se encuentra sometido a la decisión del tribunal”. ${ }^{18}$

La Corte Suprema también ha señalado de modo invariable que la culpa se construye como violación de un estándar de cuidado. En la sentencia de 26 de enero de 2004, la Corte señaló (considerando quinto): "Que la responsabilidad demandada en la especie, es la extracontractual, puesto que tiene como fuente u origen un delito o cuasidelito civil, y se encuentra regulada por los artículos 2314 y siguientes del Código Civil, disposiciones de las cuales se desprende que para que un hecho u omisión genere este tipo de responsabili$\mathrm{dad}$, es necesario que estos tengan como autor a una persona legalmente capaz, que exista una conducta dolosa o culposa, que se cause efectivamente daño, y que exista una relación

\footnotetext{
17 Pesquera Sur de Exportaciones Limitada con Esteban Salinas (1994): Corte de Apelaciones de Concepción, 25 de marzo de 1994, rol 77-93, indicador LexisNexis 22.100.

18 Aste Bonadei y otro con Larrain Vial S.A. Corredores de Bolsa (2012): Corte de Apelaciones de Santiago, 26 de abril de 2012, rol 9.128-2009.
} 
de causalidad entre los dos elementos anteriores"19. En la sentencia de Corte Suprema, 28 de diciembre de 2006. En la causa, se demandaba la muerte de Rocío Pérez Jiménez, quien el día 16 de mayo de 1998 cayó desde el cuarto piso del montacargas del edificio Torre Ligure, a través de una abertura existente entre el borde de la plataforma del mismo y una de las paredes de la caja. Dijo la Corte, en el considerando decimotercero: "De este modo, resulta que sobre dicho demandado, pesaba la obligación de cuidar, mantener, vigilar y velar por el funcionamiento eficiente de los bienes y servicios comunes, entre los que se cuenta el montacargas en que se produjo el accidente, así como ejecutar todos los actos necesarios para la conservación de estos bienes. Así, dicho demandado también actuó en forma negligente, pues incumpliendo con su deber de administración no adoptó medidas para evitar el peligro que involucraba para la seguridad física de quienes usaban el montacargas la existencia de la abertura, cuya presencia no debía serle desconocida dado que el personal subordinado a él estaba en conocimiento de ello, y en caso que ignorase, mayormente habría negligencia, porque precisamente dentro de sus deberes se encontraba vigilar y velar por el funcionamiento de los bienes y servicios comunes, y ejecutar todos los actos necesarios para su conservación. Sin duda que faltó a su obligación de administrar, porque de otro modo no se explica que solo después de producido el accidente tal como ambas partes lo sostienen se hayan adoptado medidas sobre el uso del montacargas por parte de peatones y algunas medidas de protección ante la existencia del forado" 20 .

Como se aprecia, algunos fallos de los analizados estiman que la culpa se construye desde o partir de un ilícito normativo: la culpa no es la violación de un estándar con independencia de la norma, sino que la integra ${ }^{21}$. Aunque también se ha estimado que la culpa se construye más allá del cumplimiento normativo y, por tanto, con independencia de él. Es interesante, en este sentido, el fallo de la Corte Suprema de 15 de noviembre de 2004. La Corte resolvió la demanda del trabajador por accidente del trabajo. El 12 de agosto de 1995, en las dependencias de la empresa demandada, se pretendía enderezar un cable de acero, empleando una máquina retroexcavadora; realizada la maniobra, el cable sufrió un corte, provocando diversas lesiones en la pierna del trabajador demandante. A pesar de que el empleador contaba con reglamento interno y con un sistema de prevención (se contaba por ejemplo, con un prevencionista de riesgos), la Corte reprocha la falta de control de las tareas que debían suponerse peligrosas.

\footnotetext{
19 Ariztía Comercial Limitada con Banco Sudamericano (2004): Corte Suprema, 26 de enero de 2004, rol № 2947-2002, indicador LexisNexis 29.707.

20 Pérez Veloso, Igor y otros con Inmobiliaria Paracadute Limitada (2006): Corte Suprema, 28 de diciembre de 2006, rol 3.492-2005, indicador LexisNexis 35.800.

21 Véanse en este sentido las siguientes sentencias: Perrot Agosín, Marcelo con Banco Estado (2004): Corte Suprema, 24 de marzo de 2004, rol 3.507-2002, indicador LexisNexis 29.888. El Banco incorporó al cliente por error en el Boletín de Informaciones Comerciales, demandando este los daños subsecuentes. Aunque no se expresa de la culpa como infracción del deber de cuidado, la aprecia correctamente a nuestro juicio, como un error de conducta en el que incurrieron los funcionarios del banco demandado. Mayr Adams, Miguel con Banco Chile (2006): Corte Suprema, 11 de octubre de 2006, rol 4554-2005, indicador LexisNexis 35.427. La sentencia resuelve la demanda de daños del demandante que había puesto término al contrato de cuenta corriente el año 1995 y al que se le había, sin embargo, protestado un cheque e incorporado dicho protesto en el registro de Dicom, tres años después.
} 
El razonamiento del fallo recién comentado nos parece el correcto, porque, en efecto, necesariamente, la tesis normativa de la culpa conduce a apreciar su construcción con independencia de la violación normativa y, como en el presente caso, aun cumpliendo las disposiciones legales que regulan una actividad. Es lo que falló la Corte de Apelaciones de Valdivia, en la sentencia de 10 de agosto de 2000. La Corte resuelve el problema de responsabilidad generado por la intervención de la empresa demandada en el río Gol-Gol, con el objeto de construir un terraplén en la ribera contigua del fundo El Retiro, de propiedad del demandante. Los trabajos ocasionaron erosión y pérdida de importantes terrenos y vegetación de la isla La Fortuna, de propiedad del demandante. Según la Corte, considerando duodécimo: "Que con los antecedentes aparejados al proceso, aparece con meridiana claridad que la empresa demandada Ingecol S.A. realizó las labores de extracción de áridos cumpliendo con las instrucciones emanadas del plan aprobado por el Departamento de Obras Fluviales del Ministerio de Obras Públicas, sin embargo en la realización de las labores encomendadas originó el cambio en el cauce de las aguas del río Gol Gol y por ende produjo un violento desplazamiento hacia la ribera sur, causándole daños en la propiedad de don Fernando Vergara Estrada, lo que significa que la empresa demandada ejecutó las obras, con negligencia, constitutiva de culpa y en caso alguno con dolo, ya que no puede perderse de vista que la demandada necesariamente debió prever que las condiciones que presentaba el río Gol Gol, la situación climática de la zona y los trabajos de extracción que allí se realizaban podían y debían provocar el cambio en el cauce del río y los demás hechos que causaron, con el consecuente daño al ofendido y actor". ${ }^{22}$

Interesante también resulta el fallo de la Corte de Apelaciones de Santiago, de 17 de abril de 2002. La acción indemnizatoria se fundamenta en la omisión de la demandada (Minera La Diputada Las Condes S.A.), en señalizar la existencia de cables de acero, pertenecientes a torres de alta tensión, cables en los que impactó el aspa de la hélice del helicóptero Sikorsky S55, pilotado por Juan Muñoz Moreno. La Corte construye el juicio de culpa como infracción del deber de cuidado, según la actividad. Al respecto, dijo la Corte, en el considerando decimoséptimo: "Que conforme a tales antecedentes resulta establecido el deber de cuidado de quien actuaba por la Compañía Minera La Disputada de Las Condes S.A., en orden a que sus conocimientos específicos sobre el sector, le obligaban a abstenerse de señalar a sus contratistas de la existencia de un terraplén que servía de helipuerto ocasional, puesto que estaba en antecedentes de los riesgos extraordinarios o anormales que importaba operar en ese lugar, los cuales excedían los normalmente aceptables, tanto por la cantidad de cables de tendido eléctrico existentes en el lugar, como por la falta de señalización de los mismos, o si se quiere, por el hecho que de señalarse ese lugar como helipuerto eventual, no se especificó adecuadamente los factores de riesgo desmedido del sector, esto es la existencia de multiplicidad de cables de alta tensión en el lugar, dejando de adoptar las medidas precaución mínimas que le son exigibles en tales condiciones, de acuerdo a las

22 Vergara Hernández, Darío con Sociedad Ingecol S.A. (2000): Corte de Apelaciones de Valdivia, 10 de agosto de 2000, rol 10.425-99, indicador LexisNexis 22.019. 
circunstancias y situación específica de estas personas, atendido el conocimiento que tenían del terreno". 23

De lo que viene analizándose, debe concluirse que la sola violación normativa no puede configurar culpa (a menos que la norma construya directamente el estándar, en cuyo caso nos encontramos frente a la hipótesis de culpa contra legalidad). En la sentencia de la Corte de Apelaciones de Santiago, de 11 de marzo de 2003, se dijo expresamente (considerandos segundo a cuarto): "20) Que la apelante basa esencialmente su pretensión en la discriminación de género arbitraria experimentada por ella con motivo de la convocatoria para la provisión de un cargo, por parte de una empresa privada, con infracción de diversas normas, contenidas tanto en la Carta Fundamental como en tratados internacionales ratificados por Chile y vigentes y aun en disposiciones de rango simplemente legal, que prohíben cualquiera discriminación fundada entre otros, en motivos de raza, sexo u opinión política, y que no tengan por causa la capacidad o idoneidad personal del interesado. $3^{\circ}$ ) Que la recurrente limita su apelación en el petitorio de su recurso, a lo resuelto en el fallo en alzada respecto de "Almacenes París Comercial S.A.", por lo cual no cabe entrar en consideraciones respecto del ilícito civil imputado en el libelo a la segunda demandada, identificada en la reflexión $1^{\mathrm{a}}$ precedente. $4^{\mathrm{o}}$ ) Que en el fondo del planteamiento de la actora y apelante subyace la idea de que la simple transgresión de la normativa garantística de todas las personas a la libertad de trabajo y su protección, conllevaría el derecho a una indemnización automática de los perjuicios ocasionados, siendo suficiente al efecto con el simple establecimiento de la relación de causalidad existente entre el hecho ilícito constituido por la contravención legal y el resultado dañoso producido". ${ }^{24}$

Ahora bien, que exista relativo consenso en la dogmática, no implica que tal construcción carezca de algunos defectos sobre los que no se ha reflexionado suficientemente. Nuestro propósito, por tanto, es aproximarnos a algunos de dichos problemas.

\section{LA CULPA COMO MECANISMO DE DISTRIBUCIÓN DE RIESGOS: ANÁLISIS JURISPRUDENCIAL}

De lo que ha venido exponiéndose, a nuestro juicio, la culpa se emplea como herramienta de distribución de riesgos en una sociedad. Concretamente, estimamos que la culpa

\footnotetext{
23 Santibánez Antunes, Edgardo y otro con Compañia Minera La Diputada de Las Condes S.A. (2002): Corte de Apelaciones de Santiago, 17 de abril de 2002, rol 2.802-99, indicador LexisNexis 21.425.

24 Singh Cornejo, Maria Teresa con Almacenes París Comercial S.A. y El Mercurio SA (2003): Corte de Apelaciones de Santiago, 11 de marzo de 2003, rol 4.809-1999, indicador LexisNexis 28.524. La demandante pretendía se indemnizara los perjuicios derivados del aviso para la contratación de auditor interno en tiendas Almacenes París, publicado en El Mercurio, cuya convocatoria era solo para varones, con una edad máxima de 26 años e incluía la exigencia de presentar una fotografía reciente del postulante. Véase también, Coria Huerta, Jorge con Cortés y Aguilera Cía. Limitada (2002): Corte de Apelaciones de Santiago, de 10 de julio de 2002, indicador Microjuris MJJ7596, RDJ7596. En el fallo se define la culpa con arreglo al artículo 44. Según la Corte, considerando diecinueve: "Que, por otra parte, la culpa o descuido es un hecho jurídico definido por el legislador en el artículo 44 del Código Civil, entendiendo por leve "la falta de aquella diligencia y cuidado que los hombres emplean ordinariamente en sus negocios propios. Culpa o descuido, sin otra calificación, significa culpa o descuido leve. Esta especie de culpa se opone a la diligencia o cuidado ordinario mediano".
} 
delimita un radio de actividades de las que el potencial autor del daño debe hacerse cargo, reservando un ámbito en el que la propia víctima debe asumir su propio cuidado.

Ello quiere decir, en consecuencia, que entre culpa y responsabilidad estricta existe una diferencia cualitativa, sino más bien cuantitativa. Como veremos, el verdadero problema de la construcción del estándar en la culpa, es transformar este critero de imputación en una íntegra asignación de riesgos para el autor del daño. En otras palabras, frente al desarrollo de determinada actividad, estaremos frente a una responsabilidad estricta siempre que la totalidad de los riesgos sean asumidos por el autor del daño; por el contrario, la víctima no tiene posibilidad de asumir medidas de cuidado o estas son marginales. Ello explica que la responsabilidad estricta se consagre precisamente en actividades en las que el potencial riesgo es inherente a la actividad. Es decir, siguiendo en este punto a Barros, las diferencias entre un sistema por culpa y otro de responsabilidad estricta radica en el enfoque: mientras el régimen de culpa -aunque presunta- se focaliza en la conducta del agente, la responsabilidad estricta atiende al defecto de unidad que resulta de la actividad. ${ }^{25}$

Esta perspectiva ha sido sostenida, por ejemplo, por Medina Alcoz, para quien el sistema de responsabilidad contiene dos principios que pueden diferenciarse claramente: el de la culpa y el del riesgo derivado de actividades peligrosas. Para la autora, la responsabilidad por riesgo supone una actividad peligrosa en sí misma, en la que se entiende integrada la idea de culpa. ${ }^{26}$ Como dice Barros: "La responsabilidad por culpa tiene un elemento objetivo que la aleja del reproche personal; pero esa objetividad es radicalizada en el caso de la responsabilidad estricta, porque esta no siquiera requiere que la conducta sea objetivamente reprochable". ${ }^{27}$

La perspectiva que viene defendiéndose había sido sustentada desde el análisis económico del Derecho. Mirado así el problema, la responsabilidad estricta y el sistema de negligencia tienen distintos efectos sobre el comportamiento de la víctima y el ofensor. La responsabilidad estricta entrega al potencial dañador incentivos para reducir su actividad, cuando ello implica menos coste que adoptar niveles de cuidado, porque de otro modo soportaría los costos de un accidente que podría ser evitado por tales ajustes. La víctima, en cambio, no tiene incentivos para reducir su actividad. En las reglas que gobiernan la negligencia, en cambio, el potencial dañador no tiene incentivos para ajustar su actividad, porque la víctima no es compensada por cualquier daño que ocurra, a menos que podría haber sido evitado por el dañado siendo más cuidadoso, en vez de reducir su actividad. ${ }^{28}$

\footnotetext{
25 Barros (2009) pp. 448 y ss.

26 Medina (2004) pp. 3219 y ss. Sobre el tema véase Medina (2003) pp. 57 y ss. Un planteamiento similar ha sostenido RegLero (2008) pp. 2283-2285, quien estima que el ordenamiento español contiene un problema al no contemplar una norma general de imputación por riesgos, de modo que la culpa, al tener unos límites poco definidos, sigue constituyendo un criterio perfectamente válido para las situaciones de riesgo. Para un sistema como el del common law, véase Owen (1997) pp. 201-202.

27 Barros (2009) pp. 445.

28 Como plantean Salvador y Castiñeira (1997) pp. 115; 150, la negligencia influye en la calidad de la conducta; las reglas de responsabilidad estricta en la cantidad. Según estos autores, en el sistema de la negligencia, el dañante está sometido a un estándar de cuidado que debe emplear para la prevención del daño. Si se cambia el modelo, el sujeto no modificará su estándar de cuidado, no le forzará a adoptar precauciones, que eran las optimas bajo el régimen de negligencia, pero dado que ahora deberá indemnizar daños que no habría cubierto
} 
De este modo, la responsabilidad estricta podría ser aceptada solo cuando el ajuste en la actividad del demandado, no del demandante, puede ser un método eficiente para evitar el accidente; en el caso contrario, es decir, cuando el supuesto no es la reducción de la actividad, sino el cuidado que debe emplearse, debe ser elegido el sistema de negligencia $^{29}$. Como indican Salvador y Castiñeira: “...para que un sistema de responsabilidad objetiva cree los incentivos económicamente correctos para minimizar los costes sociales de los accidentes, es preciso que sea únicamente el causante potencial de los daños quien pueda contribuir a reducir el número y gravedad (causación unilateral de daños), así como que la compensación sea perfecta (...) pero si la víctima potencial también podría haber hecho algo para prevenir o disminuir accidentes, un régimen de responsabilidad objetiva es el detonante de una explosión de daños"30.

Veamos en la jurisprudencia de qué modo la culpa constituye una herramienta para distribuir riesgos. En la sentencia de la Corte Suprema, de 15 de noviembre de 2004, a propósito de un accidente de trabajo, la Corte fijó el estándar de conducta en un punto que tocaba al trabajador asumir ciertas medidas de cuidado. Según la Corte, si el empleador delimita la zona y pone un capataz a cargo, el accidente se debe a responsabilidad propia del trabajador si vulnera tales reglas: "Decimocuarto: Que las áreas de trabajo en el lugar de las obras estaban delimitadas, por lo que disminuiría el riesgo para los trabajadores por las faenas realizadas. Decimoquinto: Que entonces, las lesiones que sufrió el actor por el golpe que recibió mientras trabajadores de la empresa estiraban un cable de fierro se produjeron por su propio descuido, pues al estar laborando por más de 10 años en la empresa y ser el trabajador más antiguo en el lugar, no podía menos que conocer la dinámica interna de trabajo y la forma de realización de las diversas tareas, habida consideración asimismo que él fue quien proporcionó el material que posteriormente comenzaron a preparar los trabajadores. Decimosexto: Que el procedimiento empleado por los enfierradores para esta tarea era uno de los que se usaba en este trabajo y la maquinaria utilizada era la apropiada, de acuerdo a lo consignado en los antecedentes agregados al peritaje. Decimoséptimo: Que como se indicó, la empresa contaba con experto en prevención de riesgos y se había entregado a los trabajadores el reglamento interno de orden y seguridad, circunstancias que refuerzan las conclusiones anteriores y permiten asimismo, adquirir la convicción que no existió la negligencia y falta de cuidado que imputa el actor a la demandada" 31 .

Siempre a propósito de los accidentes de trabajo, es interesante la sentencia de la Corte Suprema, de 12 de octubre de 2006. El 6 de febrero de 2004, el demandante había

en la hipótesis de responsabilidad por culpa, subirá como sus precios, bajará la demanda y, en consecuencia, habrá menos actividad. Véase también el interesante análisis a la jurisprudencia del TJCE y la jurisprudencia alemana en el que se formulan consideraciones similares. SAlvador Coderch (2001) pp. 7-8.

29 Landes y Posner (1987) pp. 69-70. En un sentido similar véase el trabajo de SHavell (1980) pp. 1-9, recopilado en Posner y PARISI (1997) pp. 333-341, quien realiza dos aproximaciones a las tipologías de accidentes: unilateral y bilateral, de acuerdo con el grado de participación del dañante-dañado. En una hipótesis unilateral, cuando las víctimas potenciales nada pueden hacer para impedir o prevenir el accidente o bilateral, si dichas víctimas pueden influir en el desencadenamiento del accidente.

30 Salvador y Castiñeira (1997) pp. 151-152.

31 Luengo Poblete, Marcos con Navarrete Díaz Cumsille Ingenieros Civiles (2004): Corte Suprema, 15 de noviembre de 2004, rol 4.019-2003, indicador LexisNexis 31.392. 
subido a una andamio en el que estaba trabajando, sufriendo TEC abierto, pérdida parcial de la visión e inutilización de la muñeca izquierda. Aunque empleador alegó haber cumplido con las necesarias normas de cuidado, al haber proporcionado los elementos de seguridad al trabajador, la Corte consideró que ello no era suficiente para configurar diligencia: "La obligación del empleador de tomar todas las medidas necesarias para evitar accidentes laborales, y el deber de proporcionar los elementos de seguridad a trabajadores que desempeñan funciones peligrosas, no se cumplen con solo tener a disposición de tales trabajadores dichos elementos en una bodega, sin que nadie parezca controlar si los toman o no, sino que debe hacerse una entrega personal y controlada para cada comienzo de labor, vigilando además, en cuanto sea posible, su uso. Tampoco se cumplen con la simple entrega de un reglamento de seguridad (Considerandos 7 y 8, CA Rancagua)"32.

Otras sentencias emplean la culpa en el mismo sentido. En el fallo de la Corte de Apelaciones de Antofagasta, de 20 de julio de 2000, doña Angélica Chaile Toroco dedujo demanda civil en contra del Banco Estado de Chile y en contra Nilsa Fernández Vega, con el objeto que se le restituyeran los fondos sustraídos ilícitamente de su libreta de ahorros. Para la Corte, el estándar de conducta del banco demandado encuentra como límite la capacidad técnica de los cajeros de la institución, que según la Corte no ostentan la calidad de peritos caligráficos y advirtió que si se presenta ante los funcionarios la cédula verdadera y quien suscribe el documento tiene una firma similar a la titular, escapa del control del personal del banco determinar la identidad del girador. Según la Corte: "Séptimo: Que, por otra parte, en las cuatro oportunidades que la procesada Nilsa del Carmen Fernández Vega, concurrió al Banco del Estado a retirar dinero, contrahizo la firma y presentó la cédula verdadera, de donde resulta entonces que los funcionarios de la entidad bancaria, al solicitarle este documento, tomaron la precaución debida, no pudiendo imputárseles negligencia en su actuar, pues no se había comunicado la pérdida o sustracción de la libreta y la cédula de identidad era verdadera, y como la firma era similar a la de la titular, puesto que fue imitada y los funcionarios de aquella no son peritos calígrafos, su conducta se encuentra exenta de reproche, por lo que ninguna responsabilidad les asiste y, en consecuencia, tampoco al Banco del Estado, su empleador que fue demandado". Como se aprecia, además, se hace una valoración de la conducta de la propia víctima, quien no avisó oportunamente de la pérdida de su documento de identidad (como lo exigía una de las cláusulas del contrato), informando al banco de la situación un mes después de la pérdida, cuando los giros se habían efectuado. ${ }^{33}$

Otro caso interesante es el resuelto por la Corte de Apelaciones de Santiago, en sentencia de 24 de agosto de 2012. Fallando un recurso de nulidad deducido por el empleador, a propósito de un accidente de trabajo, dijo la Corte, citando a Barros: “4º Que, como se advierte, la disposición que se denuncia conculcada, en lo que interesa, hace surgir la responsabilidad del empleador cuando el accidente se deba a su "culpa". Conforme a lo que previene el artículo 44 del Código Civil, "culpa o descuido”, sin otra calificación,

32 Calderón con ACM Limitada (2006): Corte Suprema, rol 3995-2006, indicador LexisNexis 3995-2006.

33 Chaile Toroco, Angélica con Banco Estado y Nilsa Fernández Vega (2000): Corte de Apelaciones de Antofagasta, 20 de julio de 2000, rol 15.763-00, indicador LexisNexis 19.476. 
significa culpa o descuido leve, que es precisamente, según dicha norma, la falta de aquella diligencia y cuidado que los hombres emplean ordinariamente en sus negocios propios, y que se opone a la diligencia o cuidado ordinario o mediano. En consecuencia, el empleador debe responder de culpa leve y "ello no significa que deba emplearse en la seguridad de los trabajadores el mismo nivel relativo de cuidado que el exigido para proteger, por ejemplo, la integridad de las cosas. De acuerdo con las reglas generales, el nivel de cuidado exigible depende del valor de los bienes jurídicos amenazados por la conducta del responsable. El estándar de diligencia del empresario prudente y diligente asume que este adopta las prevenciones en consideración de la entidad de los bienes comprometidos”. ${ }^{34}$

¿Cuáles son los riesgos de los que debe responderse a título de culpa? Hemos encontrado una sentencia que, en esta materia, es bastante ilustrativa de la clase de riesgos que deben ser considerados para construir el reproche de culpa. Nos referimos al fallo de la Corte de Apelaciones de Santiago, de 7 de septiembre de 2000. La Corte resuelve el problema de responsabilidad que genera la construcción de un edificio en el predio colindante. Para la Corte, la demandada acreditó que de modo general acreditó el empleo de procedimientos adecuados, pero en atención de las circunstancias concretas de la causa, no realizó los estudios necesarios para precaver el daño, en atención a las peculiaridades del predio vecino. En el considerando quinto, la Corte razonó en este sentido: "Que, del análisis de la prueba rendida en autos, se debe concluir que la sociedad constructora demandada si bien ha aportado prueba suficiente para acreditar que se empleó en general el procedimiento adecuado para impedir que se produjeren daños en las construcciones vecinas, no ha aportado prueba alguna para demostrar que hizo lo necesario para impedir que ocurriera el daño en la construcción de la demandada, atendido su tipo, calidad y condición. En efecto, la propia sociedad constructora, en su escrito de contestación a la demanda corriente a fojas 111 de autos, ha dicho que el daño provocado se produjo con motivo de que las dependencias de servicio de la casa de la demandante, están construidas sin una correcta unión estructural con el muro divisorio, es decir, están simplemente adosadas sin los pilares correspondientes. Pues bien, si la empresa constructora demandada tuvo conocimiento de tal hecho o defecto constructivo antes de iniciar la excavación, no se entiende por qué razón no adoptó las medidas tendientes a impedir el daño que, en tales condiciones, se podía prever. Y, por otra parte, si desconocía tal hecho o defecto, fue porque no realizó los estudios necesarios para determinar los efectos que los trabajos de excavación podrían producirse en las sobredichas construcciones, atendida su condición. En todo caso, la empresa constructora demandada no aportó prueba alguna al respecto". ${ }^{35}$

Finalmente, es claro que esta perspectiva de distribución de riesgos, también se aprecia desde la denominada culpa de la víctima. Muy ilustrativo es el fallo de la Corte

34 Cerda con Textiles Lanabel Limitada (2012): Corte de Apelaciones de Santiago, 24 de agosto de 2012, rol 282-12, indicador Microjuris MJJ33208.

35 Araneda con Viviendas Económicas Barrio Alto S.A. (2000): Corte de Apelaciones de Santiago, 7 de septiembre de 2000, rol 2.159-1997, indicador LegalPublishing CL/JUR/1864/2000; 21059. También puede servir de ejemplo el fallo de la Corte de Apelaciones de Santiago, de 17 de abril de 2002, antes citado, puesto que el juicio de culpa contra la empresa minera La Disputada Las Condes S.A. se fundó en la determinación de los riesgos concretos que debieron haberse evitado. 
Suprema, de 31 de julio de 2006. La Corte entendió que no podía configurarse la culpa, porque con arreglo al estándar de conducta objetiva, no podía preverse que un sujeto bajaría en silla de ruedas escaleras mecánicas. Según la Corte: "Para que haya un acto culposo debe existir descuido o negligencia en el proceder de un sujeto, entendiéndose por tales la falta de aquella diligencia o cuidado que los hombres prudentes emplean ordinariamente en sus actos y negocios propios. Esto supone un error de conducta, imprudencia, negligencia y falta de una mínima precaución, circunstancias todas que no concurren cuando la causa única y exclusiva del daño sufrido por la actora fue su propia acción imprudente, según el criterio de normalidad, creando para la demandada un deber de advertencia que no le es exigible, desde que a nadie le es obligatorio advertir de la peligrosidad de la acción que, por su propia naturaleza y de acuerdo a la previsibilidad de una persona normal resulta imprudente. En efecto, no es racional bajar en silla de ruedas a través de una escalera mecánica, ya que ninguno de estos dos elementos están hechos para un uso compatible y simultáneo". ${ }^{36}$ El fallo es interesante, además, porque descarta que la culpa suponga la evitación de todo peligro, encontrándose el límite en aquello que normalmente no resulta una actividad riesgosa (el uso de una escalera mecánica), a menos que se emplee de modo imprudente por la propia víctima. ${ }^{37}$ Ello nos sirve de antesala para abordar el grave problema que supone extender el estándar para hacer responsable al autor del daño, como consecuencia de no haber previsto-evitado, todo peligro asociado a una actividad.

\section{EL EMPLEO ERRÓNEO DE LA CULPA: CRITERIO DE ATRIBUCIÓN DE TODOS LOS RIESGOS DE UNA ACTIVIDAD}

Entre otras razones, Rosso reprocha que la concepción de la culpa normativa suponga la construcción de deberes por parte del juez, porque ello lo transformaría en una suerte de legislador. ${ }^{38}$ A nuestro juicio, con independencia de la cuestión relativa a las fuentes de los deberes jurídicas, la crítica apunta a un problema más profundo en la concepción normativa de la culpa: y es que, en efecto, el juez puede elevar el nivel o grado del estándar de la diligencia siempre un poco más allá del estándar normativo y, en ausencia de este, siempre pueda colocar dicho estándar hacia una conducta que importe mayor exigencia, abandonando precisamente la función propia de la culpa, como criterio de distribución de riesgos, conforme a un patrón medio o, si se quiere, con arreglo al patrón de la culpa leve. En algunos ámbitos, como la responsabilidad por accidentes de trabajo, algunos autores ya

\footnotetext{
36 Abarca Venegas, Nancy con Plaza Vespucio S.A. (2006): Corte Suprema, 31 de julio de 2006, rol 3.246-2005, indicador Microjuris MJJ17969, RDJ17969.

37 Puede verse entonces la estrecha relación entre culpa y la participación de la víctima. El debate acerca de si esta cuestión, es decir, culpa de la víctima, corresponde a un problema de culpa o problema causal, lo hemos abordado en nuestro trabajo AEDO (2013) pp. 505-525. A nuestro modo de ver, advertir un enfoque desde imputación objetiva no descarta automáticamente que la culpa de la víctima suponga una valoración o incida en la valoración de la culpa, puesto que ello supondría resolver antes las relaciones culpa-causalidad, materia de suyo compleja y que hemos analizado parcialmente en AEDO (2012) pp. 791-795.

38 El autor considera un error conceptualizar en cualquier caso la culpa como infracción del deber de cuidado. Véase Rosso (2008) pp. 704-705.
} 
han manifestado este problema, al sostener que la jurisprudencia ha conducido a hacer responsable al empleador por la culpa levísima. ${ }^{39}$

Con todo, el problema tiene carácter más general, en el sentido de que el juez siempre puede elevar el estándar de la diligencia fuera del radio de los estrictos deberes normativos (o en ausencia de ellos). Veamos algunas sentencias en este sentido.

En materia de accidentes de trabajo, nos parece paradigmática la sentencia de 15 de julio de 1997. La Corte de Apelaciones de Santiago resolvió la demanda del trabajador que, habiéndosele ordenado el depósito de importantes sumas de dinero de la empresa, fue asaltado. Según la Corte: "Que la empleadora no cumplió la obligación de procurar todas las medidas necesarias para proteger eficazmente la vida e integridad física y mental del actor en el desempeño de sus funciones, obligación inequívocamente comprendida en el contrato de trabajo, acto que incuestionablemente está caracterizado por culpa, sobre todo si se advierte claramente la omisión del demandado consistente en no haber proporcionado al actor alguna medida de protección cuando le fuera encomendado el depósito bancario de una apreciable suma de dinero en efectivo, en circunstancias que es público y notorio el incremento de delitos contra la propiedad perpetrados mediante actos de violencia (Considerandos Primero y Cuarto, Corte de Apelaciones de Santiago)" ${ }^{40}$

Pero en otros ámbitos también la culpa se ha empleado para hacer responder de todos los riesgos derivados de la actividad. En primer lugar, nos parece que se mueve en esta línea la sentencia de la Corte Suprema de 7 de septiembre de 2006. Los hechos que dieron lugar a la controversia, fueron los siguientes: a) el día 27 de enero de 2003 la menor Nadia Sofía Villegas Bahamonde, en circunstancias que transitaba por el techo de un galpón ubicado en la localidad de Chilca sufrió severas quemaduras de origen eléctrico en el rostro. b) bajo las líneas eléctricas causantes del accidente se encontraba el galpón hasta donde habría trepado la menor el día del accidente. c) las líneas que abastecían de electricidad al predio son de propiedad de Luz Osorno.

La Corte estimó que la culpa se configuraba en función de la altura en la que estaban ubicados los cables que electrocutaron a la menor, pero no considera la culpa de la víctima, al sostener que aun respetando la altura, la empresa debía adoptar las medidas para evitar todo peligro; reprochando además la falta evidente de negligencia, por no ficalizar el lugar en un lapso de treinta años. Dijo la Corte: "Decimoctavo: Que, el segundo elemento que compete analizar es la concurrencia de culpa en el obrar de la demandada evidenciada en no haber adoptado las medidas de seguridad necesarias para evitar la ocurrencia de siniestros, en concreto habría consistido en que la demandada no mantuvo las líneas en un estado que no cause peligro a terceros, así los cables estaban muy cerca del techo y, habrían sido instalados luego de haberse edificado la construcción". Y, en subsidio de esta cuestión consideró la falta de fiscalización como constitutiva de culpa: "Vigésimo segundo: Que, sin perjuicio de lo expuesto resulta evidente que aún de mediar tal misiva en forma previa al

\footnotetext{
39 Diez (2005) p. 85. O incluso, a la exigencia de cubrir riesgos que no se encuentran directamente asociados a la actividad laboral.

40 López Marchant con Cinema Video S.A. (1997): Corte de Apelaciones de Santiago, 15 de julio de 1997, rol 1.228, indicador LexisNexis 14.654 .
} 
accidente resulta a todas luces insuficiente para la exención de culpa dada la gravedad de la situación de peligro creada por la demandada, su mantención en el tiempo cerca de 30 años, lo que devela una negligente fiscalización, pues se encontraba en situación de remediar y extinguir el riesgo". ${ }^{41}$

Puede apreciarse un doble análisis de la culpa: por un lado, culpa equivale o, dicho de otro modo, el estándar se eleva a la evitación de todo peligro, solo por la circunstancia de no respetar la altura adecuada. En ausencia del primer argumento, para la Corte, la culpa se construye por la falta de supervigilancia continúa, determinando un estándar de actuación para las actividades empresariales.

Del mismo modo, en la sentencia de la Corte Suprema, de 1 de abril de 2004, se elevó la culpa hasta emplearla como mecanismo de responsabilidad estricta, por cuanto exige a la empresa adoptar las medidas para eliminar completamente los ruidos molestos que afectaba a la demandante. Dice la sentencia: "Habiendo reconocido la demandada ser causante del daño descrito, en cuanto continúan los ruidos generados por la actividad comercial de la demandada, como también que a consecuencia de esta situación han recibido sanciones y órdenes de la autoridad para corregirlos, no queda más que dejar establecida la negligencia de la empresa demandada por no haber adoptado las medidas necesarias para eliminar completamente el ruido que ocasiona daño a su vecino y de conformidad al artículo 2.314 del Código Civil, está obligada a la indemnización de los perjuicios. En efecto, el demandado no acreditó la desaparición de los ruidos reclamados por el actor, y reconocidos por su parte, estableciéndose la existencia de ruidos molestos para el actor, y que la actuación de la empresa demandada fue negligente, al no haber adoptado las medidas necesarias para eliminar completamente el ruido que ocasionaba molestias al actor". ${ }^{42}$

En los fallos que hemos citado, la culpa se utiliza, repetimos, como mecanismo encubierto de responsabilidad estricta, cuestión que desvirtúa la naturaleza del instituto y que altera el régimen previsto por el legislador. En todo caso, subsiste el problema de enfrentarse a hipótesis en que la actividad es potencial o intrínsecamente peligrosa, no obstante no existir un sistema de responsabilidad estricta consagrado legalmente.

Nos parece que frente a situaciones de esa naturaleza, la decisión que analizaremos seguidamente explora un camino adecuado, por cuanto, respetando el presupuesto de la culpa se recurre a la presunción por hecho propio que un sector de la doctrina deduce del artículo 2329.43 En este punto, debemos estar completamente de acuerdo, aunque por

41 Villegas con Cía. Eléctrica Osorno (2006): Corte Suprema de 7 de septiembre de 2006, rol 38/2006, indicador LexisNexis 35252.

42 Villarroel con Supermercados Korlaet (2004): Corte Suprema, 1 de abril de 2004, rol 3.942, indicador LexisNexis 30.006 .

43 Desde luego, no podemos detenernos en las posiciones doctrinales que se han pronunciado sobre el punto. Rodríguez Grez (1999) pp. 210-211, como defensor más reciente, cree que la regla del artículo 2329 es mera repetición del artículo 2314. Aun cuando Alessandri, como Ducci, a nuestro juicio plantean la cuestión de modo confuso, cuando exigen que debe presumirse cuando por las circunstancias el hecho se deba a culpa, el argumento apunta a la construcción de la presunción a partir de hecho intrínsecamente peligrosos. Dice al respecto Alessandri: "La víctima de un choque de esta especie no necesita probar la culpa de la empresa o de sus dependientes, le bastará acreditar el choque y el daño que sufrió a consecuencias de él”. Véase ALESSANDRI (2005) números 195-196, pp. 212-213. DuCCI (1971) p. 134. Corral (2004) p. 229 critica a la posición ante- 
razones distintas, como veremos luego, con Tapia, quien ha defendido la aplicación de la presunción, precisamente, a los casos en que la actividad resulta potencialmente peligrosa. ${ }^{44}$

En un interesantísimo fallo, la Corte de Apelaciones de Concepción, en la sentencia de 23 de julio de $1993,{ }^{45}$ resolvió la aplicación de la presunción de culpa por hecho propio del artículo 2329, bajo los siguientes supuestos. Entre el 28 de abril y el 11 de mayo de 1989, se produjeron dos incendios forestales iniciados por el demandado para el control de pastizales, incendios que afectaron seriamente a los predios de los demandantes. Para la Corte: "Que forma parte de la experiencia común, que el uso del fuego como medios de limpieza de terrenos rústicos es una actividad de suyo extremadamente peligrosa, en particular en una zona como la de la Octava Región, eminentemente forestal. Por lo mismo, de acuerdo a la probabilidad normal, según aquella experiencia, un incendio producido por el fuego proveniente de un roce ha de entenderse culpable, salvo prueba de haberse empleado la diligencia debida. Esta conclusión se apoya en el recto entendimiento del artículo 2329 del Código Civil, así como en los principios generales de la prueba. En efecto, de aquella disposición deriva que, en presencia de actividades que de suyo son peligrosas, los resultados dañinos de ellas han de entenderse imputables a culpa del que realiza tal actividad, porque ellas generan normalmente daños cuando no se emplea la debida diligencia (considerando noveno)". ${ }^{46}$

Al margen del ejemplo que ofrecemos en este artículo, los trabajos de Schiele y Tocornal, así como el de Tapia, han probado, a nuestro juicio, que el artículo 2329 tiene aplicación en la jurisprudencia en los casos de actividades de peligro intrínseco. ${ }^{47}$

Advertimos en el artículo de estas autoras, tres grupos de casos. Unos, en los que la jurisprudencia afirma la presunción en situaciones en que la culpa de uno de los autores del daño se configura como culpa contra legalidad. Nos referimos especialmente a situaciones de accidentes de tránsito. En estos supuestos, la culpa del conductor se configura como violación normativa y tratándose de aquellos que generan situaciones de peligro, que provocan el accidente de tránsito, se presume la culpa en virtud del artículo 2329.48 Otros, en que

rior que se trata de una posición tautológica. Para Corral, el inciso primero debe contiene la exigencia de causalidad, mientras que el inciso segundo contiene presunciones de causalidad, antes que de culpa.

44 TAPIA (2009) pp. 692; 701.

45 La sentencia es también citada por TAPIA (2009), cit. (n. 54), p. 700.

46 San Martín Millar, Audilia y otro con Grandón Concha, Juan Alberto (1993): Corte de Apelaciones de Concepción, 23 de julio de 1993, indicador Microjuris MJJ2267, RDJ2267. En el Derecho romano había supuestos en los que la culpa se empleaba para extender el ámbito de aplicación de la iniuria, en aquellas hipótesis en las que a pesar de haber una conducta de iure debía responderse; o bien, para limitar la extensión de la iniuria, esto es, en aquellos supuestos en los que aun actuando contra una norma -un deber determinado-, la conducta no podía ser reprochada. Zimmermann (1996) p. 1005, explica que había casos en los que no podía decirse que el autor había actuado iure, pero en los cuales resultaba irracional imponer la responsabilidad. Cita algunas decisiones, como el pasaje del D. 9, 2, 30, 3, precisamente caso en el que si alguien prendía fuego a su rastrojo o zarzal para quemarlo y este se expandía, causando daño a su vecino, la imposición de responsabilidad solo se hacía efectiva en el supuesto de existencia de una falta de control o cuidado para evitar el daño, es decir, en un supuesto de culpa, con independencia de la iniuria.

47 Nos referimos al trabajo Schiele y Tocornal (2010) pp. 123-139.

48 Como por ejemplo, en la sentencia de la Corte de Apelaciones de Concepción, de 6 de octubre de 2008, citada por Schiele y Tocornal (2010) pp. 134 y 135. El conductor realizó una maniobra peligrosa en una zona 
la presunción es aplicada en hipótesis que se encuadraban, directa e indirectamente, en los numerales de la disposición. ${ }^{49}$ Finalmente, en un tercer grupo, la presunción se ha aplicado a actividades de peligro intrínseco, aun cuando no se puedan encuadrar en alguna de las hipótesis enumeradas en el artículo $2329 .{ }^{50}$ Tapia, por su parte, hace su propia sistematización, pero que en líneas generales puede seguir la precedentemente expuesta. ${ }^{51}$

Una parte importante de la doctrina reciente, no obstante concluir, como se hace en este artículo, que la presunción del artículo 2329 supone actividades intrínsecamente peligrosas, admiten junto con ello una presunción general de responsabilidad por hecho propio, en atención al principio re ipsa loquitur. Por todos, Barros, quien señala: "la regla de presunción de culpa por el hecho propio tiene su antecedente más general en una máxima fundada en la experiencia: el solo hecho del accidente puede ser indicio prima facie de la culpa de quien desarrolla la actividad. La máxima latina res ipsa loquitur, dejad que las cosas hablen por sí mismas, que se emplea en el common law, es expresiva de la condición de aplicación más general de la presunción: la experiencia enseña que en ciertos casos el daño puede ser más bien atribuido a negligencia que a un hecho que escapa al cuidado del agente". ${ }^{52}$ Schiele y Tocornal también consideran que la presunción puede tener aplicación general en el sentido que se ha señalado. ${ }^{53}$

Tapia ha dado excelentes razones, a nuestro juicio, para descartar la aplicación de la presunción general y, entre otros argumentos, ha denunciado la pretensión de construir un sistema de responsabilidad estricta al margen de la prescripción legal. ${ }^{54}$ No consideramos necesario repetir los argumentos de este autor, así como nuestra diversa convicción sobre el concepto de la culpa, ${ }^{55}$ pero precisamente esa perspectiva es la que nos hace argumentar también contra la presunción general de culpa por hecho propio, porque si este elemento se traduce en una distribución de riesgos sociales, no puede pretenderse que tales riesgos sean cargados siempre por el autor del daño, a menos que una razón, como la actividad potencial o intrínsecamente peligrosa, así lo justifique y, en este sentido, la presunción deberá siempre aplicarse restringidamente, tal como lo ha venido haciendo nuestra jurisprudencia.

de excavaciones encargadas por la Ilustre Municipalidad de Lota. Respecto del primero, se configuró la culpa contra legalidad; para el caso del Municipio, la Corte presumió la culpa.

49 Como los fallos de la Corte Suprema, 2 de noviembre de 2000; Corte Suprema, 28 de diciembre de 2000; Corte Suprema, 7 de mayo de 2001; Corte Suprema, 7 de mayo de 2002, en Schiele y Tocornal, (2010) pp. 128-133.

50 Especialmente la sentencia de la Corte Suprema, de 3 de noviembre de 1998, en SChiele y Tocornal (2010) pp. 125-127.

51 TAPiA (2009) pp. 696-701. Así, las hipótesis de mantenimientos de vías públicas, pueden asemejarse a las hipótesis previstas en el mismo 2329 y otros en la actividad es intrínsecamente peligrosa, aunque no pueda relacionarse con los numerales, como el almacenamiento de sustancias peligrosas o suministros.

52 Barros (2009) p. 153.

53 SChiele y Tocornal (2010) p. 139.

54 TAPIA (2009) pp. 694-695; 703.

55 Para esta materia, remitimos a nuestro trabajo AEdo (2012) pp. 781-784. 


\section{CONCLUSIONES}

Del análisis jurisprudencial, puede concluirse lo siguiente:

1. La jurisprudencia chilena admite la construcción dogmática de la denominada culpa normativa, bien mediante el expediente de la culpa contra legalidad, bien acogiendo el concepto normativo sustancial;

2. El concepto normativo sustancial importa la construcción de un estándar de comportamiento, con independencia de la violación normativa (fallos de la Corte Suprema, 15 de noviembre de 2004; Corte de Santiago, 17 de abril de 2002 y 11 de marzo de 2003), incluso a pesar de haberse alegado cumplimiento normativo (Corte de Valdivia, 10 de agosto de 2000);

3. Sin embargo, en algunas oportunidades, los tribunales han considerado erróneamente, a nuestro juicio, que la culpa siempre envuelve ilegalidad del acto (Corte Suprema, 26 de enero y 24 de marzo de 2004; 11 de octubre de 2006), o se ha estimado que, por el contrario, el cumplimiento normativo envuelve automáticamente diligencia (Corte de Copiapó, 6 de julio de 2006);

4. La culpa, entendida como reproche por la vulneración de un estándar de comportamiento, conforme a un patrón medio, se traduce en un mecanismo de distribución de riesgos sociales, estableciendo un ámbito en que el potencial dañante debe responder y un ámbito en que la propia víctima debe adoptar medidas de precaución;

5. El criterio así sostenido, ha sido empleado por la jurisprudencia chilena, para delimitar el ámbito de riesgos de los que responde el autor. Puede, al efecto, concluirse lo siguiente: a) los riesgos siempre están asociados a la actividad; b) se trata de los riesgos concretos de la actividad (Corte Suprema, 11 de enero de 2004, 12 de octubre de 2006; Corte de Apelaciones de Antofagasta, 20 de julio de 2000; Corte de Santiago, 24 de agosto de 2012);

6. Uno de los problemas del concepto normativo de la culpa, se relaciona con la deformación de su concepto, cuando los tribunales hacen soportar al autor del daño todos los riesgos derivados de la actividad (Corte Suprema, 1 de abril de 2004; 7 de septiembre de 2006; Corte de Santiago, 15 de julio de 1997);

7. Excepcionalmente, pensamos, cuando la actividad supone una actividad de peligro intrínseco (y no se encuentra consagrada la responsabilidad estricta legalmente), puede admitirse la solución de la jurisprudencia chilena, en orden a aplicar la presunción por hecho propio establecida en el artículo 2329 (Corte de Concepción, 23 de julio de 1993). Ello implica no admitir la presunción en los casos de res ipsa loquitur de modo general, porque, a nuestro juicio, deforma la función de la culpa en el sistema de responsabilidad civil.

\section{BIBLIOGRAFÍA CITADA}

Abeliuk Manasevic, René (2003): Las obligaciones (Santiago, Editorial Jurídica de Chile, reimpresión cuarta edición).

Aedo Barrena, Cristián (2010): "El uso de estacionamientos como acto de consumo: reflexiones sobre la causalidad y la culpa. Comentario a la sentencia de la Corte de Apela- 
ciones de Antofagasta de 30 de marzo de 2010", Revista de Derecho Universidad Católica del Norte, $\mathrm{N}^{\circ} 17,1$.

Aedo Barrena, Cristián (2012): "La función de la culpa en el sistema de la responsabilidad civil: una lectura desde el Derecho romano es posible”, en Elorriaga de Bonis, Fabián (coord.), Estudios de Derecho Civil VII (Santiago, Abeledo-Perrot Thompson Reuters).

Aedo Barrena, Cristián (2013): "El tratamiento dogmático de la culpa de la víctima en la responsabilidad civil: un enfoque desde la imputación objetiva”, en Domínguez, Carmen et al. (coord.), Estudios de Derecho Civil, Jornadas Nacionales de Derecho Civil, Santa Cruz 2012 (Santiago, LegalPublishing, Thomson-Reuters).

Alcalde Rodríguez, Enrique (2013): La responsabilidad de los directores de sociedades anónimas. Responsabilidad civil y penal administrativa (Santiago, Ediciones UC).

Alessandri Rodríguez, Arturo (2005): De la responsabilidad extracontractual en el Derecho civil chileno (Santiago, Editorial Jurídica de Chile, reimpresión de la primera edición).

Barros Bourie, Enrique (2009): Tratado de Responsabilidad Extracontractual (Santiago, Editorial Jurídica de Chile, reimpresión de la primera edición).

BiAnCA, Cesare Massimo (1997): "Supervivencia de la teoría de la culpa”, trad. por Alberto Jesús Bueres, en Kemelmajer de Carlucci, Aida y Bueres, Jesús Alberto (dir.), Responsabilidad por daños en el Tercer Milenio. Homenaje al profesor Doctor Atilio Anibal Alterini (Buenos Aires, Abeledo-Perrot).

Corral Talciani, Hernán (2004): Lecciones de responsabilidad civil extracontractual (Santiago, Editorial Jurídica de Chile, reimpresión de la primera edición).

De Ángel YágÜEZ, Ricardo (1993): Tratado de responsabilidad civil (Madrid, Civitas, tercera edición).

De Ángel Yágüez, Ricardo (1995): Algunas previsiones sobre el futuro de la responsabilidad civil (con especial atención a la reparación del daño) (Madrid, Civitas).

Díez-Picazo, Luis y Gullón, Antonio (2005): Sistema de Derecho Civil, vol. II: El contrato en general. La relación obligatoria. Contratos en especial. Cuasi contratos. Enriquecimiento sin causa. Responsabilidad extracontractual (Madrid, Tecnos, quinta reimpresión novena edición).

Díez-Picazo, Luis (2001): "Culpa y riesgo en la responsabilidad civil extracontractual", en Pantaleón, Fernando (a cargo de), La responsabilidad en el Derecho (Madrid, AFDUAM).

DíEz-PiCAzo, Luis (2001): "La culpa en la responsabilidad extracontractual", en De Ángel, Ricardo e Yzquierdo Tolsada, Mariano (coords.), Estudios de Derecho civil en Homenaje al profesor Roberto López Cabana (Madrid, Dykinson).

Díez-Picazo, Luis (2011): Fundamentos del Derecho Civil Patrimonial, tomo V: La responsabilidad civil extracontractual (Madrid, Thomson-Reuters).

Diez Schwerter, José Luis (2005): "La culpa del empresario por accidentes del trabajo: modernas tendencias jurisprudenciales”, en Baraona González, Jorge y Zelaya Etchegaray, Pedro (edits.), La responsabilidad por accidentes del trabajo, en Cuadernos de Extensión Jurídica, $\mathrm{N}^{\circ}$ 10: pp. 73-98.

Ducci, Carlos (1971): Responsabilidad civil (Extra-contracontual), Memoria de prueba, Universidad de Chile (Santiago, Empresa Periodística El Imparcial). 
Guajardo Carrasco, Baltazar (2005): Aspectos de la responsabilidad civil médica. Doctrina y Jurisprudencia (Santiago, Librotecnia, segunda edición actualizada).

Jourdain, Patrice (1994): Les principes de la responsabilitè civile (Paris, Dalloz, segunda edición).

Landes, William M. y Posner, Richard A. (1987): The economic structure of Tort Law (London, Cambridge, Massachusetts, Harvard University Press).

Medina Alcoz, María (2003): La culpa de la víctima en la producción del daño extracontractual (Madrid, Dykinson).

Medina Alcoz, María (2004): "El debate histórico de la subjetividad versus la objetividad de la responsabilidad civil en Francia y su proyección en España. El equilibrio de su convivencia actual en el Derecho español”, en González Porras, J.M. Méndez González, F.P. (coords.), Libro Homenaje al profesor Manuel Albaladejo García, tomo I (Murcia, Colegio de Registradores de la Propiedad y Mercantes de España, Universidad de Murcia).

Montés Penadés, Vicente L. (2003): "Causalidad, imputación objetiva y culpa en la "concurrencia de culpas”, en Cabanillas Sánchez, Antonio y otros (coords.), Estudios jurídicos en Homenaje al profesor Luis Diez-Picazo, tomo II: Derecho Civil. Derecho de Obligaciones (Madrid, Thomson-Civitas).

Owen, David (1997): "Philosophical Foundations of fault in Tort Law", en el mismo (edit.), Philosophical foundations of Tort Law (Oxford, Clarendon Paperbacks).

Posner, Richard A. PArisi, Francesco (1997): Law and Economics: An Introduction. Volume II. Contracts, Torts and Criminal Law (Cheltenham. Lyme, The International Library of critical writings in economics).

Ramos Pazos, René (2006): De la responsabilidad extracontractual (Santiago, LexisNexis, segunda edición).

Reglero Campos, L. Fernando (2008): Tratado de Responsabilidad Civil, cap. II: Los sistemas de responsabilidad civil, tomo I (Madrid, Thomson-Aranzadi, cuarta edición).

RIPERT, Georges (1949): La règle morale dans les obligations civiles (París, LGDJ, cuarta edición).

RodotÀ, Stefano (1965): Il problema della responsabilità civile (Milano, Giuffrè).

Rodríguez Grez, Pablo (2001): Responsabilidad extracontractual (Santiago, Editorial Jurídica de Chile).

Rosso Elorriaga, Gian Franco (2008): "Negligencia, imprudencia e impericia como conceptos negativos integradores de la culpa: un intento de conceptualización”, en Guzmán Brito, Alejandro (edit. científico), Estudios de Derecho Civil III (Santiago, LegalPublishing).

Salvador Coderch, Pablo y Castiñeira Palou, María Teresa (1997): Prevenir y castigar. Libertad de información y expresión, tutela del honor y funciones del Derecho de daños (Barcelona, Marcial Pons).

Salvador Coderch, Pablo (2001): "Prevención y Derecho de Daños", en Indret No 2: pp. 1-9.

Schiele, Carolina y Tocornal, Josefina (2010): "Artículo 2329 del Código Civil. La interpretación de presunción por hechos propios existe en la jurisprudencia”, en Revista Chilena de Derecho, vol. 37, No 1: pp. 123-139.

TAPia Rodríguez, Mauricio (2009): “Contra una presunción general de culpa por el hecho propio", en Pizarro Wilson, Carlos (coord.), Estudios de Derecho Civil IV. Jornadas Nacionales de Derecho Civil, Olmué 2008 (Santiago, LegalPublishing) pp. 689-705. 
TAPIA SuÁrez, Orlando (2006): De la responsabilidad civil en general y de la responsabilidad delictual entre los contratantes (Santiago, LexisNexis, segunda edición).

VINEY, Geneviève (1965): Le déclin de la responsabilité individuelle (Paris, LGDJ).

YusefF Quirós, Gonzalo (2000): Fundamentos de la responsabilidad civil y la responsabilidad objetiva (Santiago, La Ley).

YzQuierdo Tolsada, Mariano (2008): Sistema de responsabilidad civil contractual y extracontractual (Madrid, Dykinson).

Zimmermann, Reinhard (1996): The Law of Obligations. Roman Foundations of the Civilian Tradition (Oxford, Clarendon Press).

\section{JURISPRUDENCIA CITADA}

Orrego Pardo, Emilio con Empresa de Ferrocarriles del Estado (1938): Corte de Suprema, 26 de agosto de 1938, indicador LegalPublishing CL/JUR/2/1938.

Ariztía Comercial Limitada con Banco Sudamericano (2004): Corte Suprema, 26 de enero de 2004, rol No 2947-2002, indicador LexisNexis 29.707.

Perrot Agosin, Marcelo con Banco Estado (2004): Corte Suprema, 24 de marzo de 2004, rol 3.507-2002, indicador LexisNexis 29.888.

Villarroel con Supermercados Korlaet (2004): Corte Suprema, 1 de abril de 2004, rol 3.942, indicador LexisNexis 30.006.

Luengo Poblete, Marcos con Navarrete Díaz Cumsille Ingenieros Civiles (2004): Corte Suprema, 15 de noviembre de 2004, rol 4.019-2003, indicador LexisNexis 31.392.

Calderón con ACM Limitada (2006): Corte Suprema, rol 3995-2006, indicador LexisNexis 3995-2006.

Abarca Venegas, Nancy con Plaza Vespucio S.A. (2006): Corte Suprema, 31 de julio de 2006, rol 3.246-2005, indicador Microjuris MJJ17969, RDJ17969.

Villegas con Cía. Eléctrica Osorno (2006): Corte Suprema de 7 de septiembre de 2006, rol 38/2006, indicador LexisNexis 35252.

Mayr Adams, Miguel con Banco Chile (2006): Corte Suprema, 11 de octubre de 2006, rol 4554-2005, indicador LexisNexis 35.427.

Pérez Veloso, Igor y otros con Inmobiliaria Paracadute Limitada (2006): Corte Suprema, 28 de diciembre de 2006, rol 3.492-2005, indicador LexisNexis 35.800.

Castilla y otros con Empresa Eléctrica Austral (2007): Corte Suprema, de 5 de marzo de 2007, rol 603-2006, indicador CL/JUR/5740/2007; 36120.

Compañia de Seguros Euroamérica con Esval S.A. (2012): Sentencia de la Corte Suprema, 18 de enero de 2012, rol 3391-09, indicador Microjuris MJJ30873.

\section{CORTE DE APELACIONES}

San Martín Millar, Audilia y otro con Grandón Concha, Juan Alberto (1993): Corte de Apelaciones de Concepción, 23 de julio de 1993, indicador Microjuris MJJ2267, RDJ2267.

Pesquera Sur de Exportaciones Limitada con Esteban Salinas (1994): Corte de Apelaciones de Concepción, 25 de marzo de 1994, rol 77-93, indicador LexisNexis 22.100. 
López Marchant con Cinema Video S.A. (1997): Corte de Apelaciones de Santiago, 15 de julio de 1997, rol 1.228, indicador LexisNexis 14.654.

Pérez Rivera, Rafael con Banco Santander (2000): Corte de Apelaciones de Copiapó, de 6 de julio de 2000, causa rol 6.799, indicador LexisNexis 19.529.

Chaile Toroco, Angélica con Banco Estado y Nilsa Fernández Vega (2000): Corte de Apelaciones de Antofagasta, 20 de julio de 2000, rol 15.763-00, indicador LexisNexis 19.476.

Vergara Hernández, Dario con Sociedad Ingecol S.A. (2000): Corte de Apelaciones de Valdivia, 10 de agosto de 2000, rol 10.425-99, indicador LexisNexis 22.019.

Araneda con Viviendas Económicas Barrio Alto S.A. (2000): Corte de Apelaciones de Santiago, 7 de septiembre de 2000, rol 2.159-1997, indicador LegalPublishing CL/ JUR/1864/2000; 21059.

Santibánez Antunes, Edgardo y otro con Compañia Minera La Disputada de Las Condes S.A. (2002): Corte de Apelaciones de Santiago, 17 de abril de 2002, rol 2.802-99, indicador LexisNexis 21.425.

Coria Huerta, Jorge con Cortés y Aguilera Cía. Limitada (2002): Corte de Apelaciones de Santiago, de 10 de julio de 2002, indicador Microjuris MJJ7596, RDJ7596.

Moya Jérez, Amada con Importadora y Exportadora Comercial Foto Eléctrica Flash Limitada (2002): Corte de Apelaciones de Santiago, 31 de diciembre de 2002, rol 67.454-1999.

Singh Cornejo, María Teresa con Almacenes París Comercial S.A. y El Mercurio SA (2003): Corte de Apelaciones de Santiago, 11 de marzo de 2003, rol 4.809-1999, indicador LexisNexis 28.524.

Farías Soruco con Sociedad Comercial Andalucía Limitada (2007): Corte de Apelaciones de Rancagua, 23 de julio de 2007, rol 1632-2006, indicador LegalPublishing CL/ JUR/1439/2007.

Empresa de Transportes Pucará con Fisco de Chile (2008): Corte de Apelaciones de Santiago, 10 de enero de 2008, rol 3620-03, indicador Microjuris MJJ16341.

Diaz Figueroa, Jacqueline con Zuloaga Tapia, Jeanette (2010): Corte de Apelaciones de La Serena, 26 de julio de 2010, rol 1-2010, indicador LegalPublishing CL/ JUR/4400/2010.

Aste Bonadei y otro con Larrain Vial S.A. Corredores de Bolsa (2012): Corte de Apelaciones de Santiago, 26 de abril de 2012, rol 9.128-2009.

Cerda con Textiles Lanabel Limitada (2012): Corte de Apelaciones de Santiago, 24 de agosto de 2012, rol 282-12, indicador Microjuris MJJ33208.

Zamora González, Marisol con Villela Mina, Richard (2012): Corte de Apelaciones de Antofagasta, 7 de noviembre de 2012, rol 500-12, indicador Microjuris MJJ34016. 